\title{
Kajian Semiotika Tuturan Mantra Tradisi Pertunjukkan Jaranan di Desa Perangat Baru Kecamatan Marangkayu Kabupaten Kutai Kartanegara Provinsi Kalimantan Timur
}

\author{
Tri Indrahastuti, Rizki Aditya Nurcahya, Anwar Balfas \\ Universitas Mulawarman \\ Universitas Mulawarman \\ Universitas Mulawarman \\ Email: rizkyaditya6494@ gmail.com
}

\begin{abstract}
Literature is an expression of the human person in the form of experiences, thoughts, feelings, ideas, passions, beliefs in a form of concrete images that evoke charm with language tools. Jaranan performance is a ritual art activity carried out by the community as entertainment for the people of the village of Warat Baru and also to resist reinforcements. Semiotics is a science that studies a sign and the meaning in a sign, which is divided into three types, namely icons, indexes and symbols. The purpose of this study is to describe the shape of icons, indices and symbols in the speech of the Jaranan performance mantra in Prangat Baru village, Marangkayu district, Kutai Kartanegara regency. The data collection method used in this research is qualitative research, namely observation, structured interviews, recording, and collection tools in the form of interview instruments, recordings, photos, videos, and translation. The results of the research from the data of mantra speech using semiotic analysis obtained 3 utterances in the form of the 'Prince' icon, 'Sesaji', 'incense lan sela'. Obtained 4 indexes 'Sun Puji Maring Pangeran Mugi Sometimes Mitro Sami', 'Suro Diro Joyo Diningrat Melts Dening Pangastuti', 'Enjoy the offering of supados, enjoy smoothness and protection', 'kula sukani, let Kangge eat the ringgit wayangipun kula'. Get 3 symbols 'Yellow Janur', 'Semeblak koyo Geni', 'Jabang Bayine'. Obtained 4 indexes 'Sun Puji Maring Pangeran Mugi Sometimes Mitro Sami', 'Suro Diro Joyo Diningrat Melts Dening Pangastuti', 'Enjoy the offering of supados, enjoy smoothness and protection', 'kula sukani, let Kangge eat the ringgit wayangipun kula'. Get 3 symbols 'Yellow Janur', 'Semeblak koyo Geni', 'Jabang Bayine'. Obtained 4 indexes 'Sun Puji Maring Pangeran Mugi Sometimes Mitro Sami', 'Suro Diro Joyo Diningrat Melts Dening Pangastuti', 'Enjoy the offering of supados, enjoy smoothness and protection', 'kula sukani, let Kangge eat the ringgit wayangipun kula'. Get 3 symbols 'Yellow Janur', 'Semeblak koyo Geni', 'Jabang Bayine'.
\end{abstract}

Keywords: jaranan performances, semiotics, mantra speeches

\section{PENDAHULUAN}

Sastra merupakan sebuah sistem yang mempunyai konvensi-konvesi sendiri (Pradopo 2018: 122). Dalam karya sastra banyak sekali jenis nya dengan ragam dan genre yang berbeda. Didalam terkandung banyak makna yang ditentukan oleh konvensi sastra. Sumardjo dan Saini (1997) menyatakan bahwa sastra adalah ungkapan pribadi manusia yang berupa pengalaman, pemikiran, perasaan, ide, semangat, keyakinan dalam suatu bentuk gambaran konkret yang membangkitkan pesona dengan alat bahasa. Sehingga sastra memiliki unsur-unsur berupa pikiran, pengalaman, ide, perasaan, semangat, kepercayaan (keyakinan), ekspresi atau ungkapan, bentuk dan bahasa. Salah satu jenis karya sastra yang masih ada sampai saat ini adalah sastra lisan. Sastra lisan memiliki ciri-ciri yang membedakan dengan sastra yang lain, yaitu secara lisan tergantung kepada penutur, pendengar, ruang, waktu, antara penutur dan pendengar terjadi konflik fisik, sarana komunikasi dilengkapi para linguistik, dan bersifat anonim. sastra lisan masih 
dijumpai dengan sangat unik. Salah satu sastra lisan yang paling tua di Indonesia yaitu Tuturan Mantra.

Tuturan Mantra adalah sesuatu yang lahir dari masyarakat sebagai perwujudan keyakinan atau kepercayaan seseorang terhadap sesuatu. Dalam masyarakat tradisional mantra bersatu dan menyatu dalam kehidupan sehari-hari. Setiap kelompok masyarakat tentu memiliki tradisi dalam kehidupan sosial dan budaya. seperti tradisi pertunjukkan Jaranan masyarakat Kecamatan Marangkayu. Jaranan adalah salah satu kesenian tradisional adat jawa yang didalamnya dialunkan dengan tuturan-tuturan mantra yang merupakan hasil dari seluruh rangkaian sosial dan hiburan budaya yang dijalankan oleh manusia dalam masyarakat dengan segala aktivitasnya.

Penyampaian tuturan mantra tidak dapat disampaikan atau dituturkan oleh sembarangan orang, harus orang yang memang sudah mahir dalam melakukannya. Kemahiran itu terbentuk melalui latihan dengan seorang guru yang memang sudah lama menguasai tuturan-tuturan mantra tersebut. Maka dalam tradisi pertunjukan Jaranan, orang yang mengucapkan mantra adalah seorang laki-laki yang biasa disebut "Pawang". Tuturan mantra dapat dianalisis menggunakan analisis kajian Semiotika. Semiotika adalah ilmu tentang tanda-tanda. Ilmu ini menganggap bahwa fenomena sosial atau mayarakat dan kebudayaan itu merupakan tanda-tanda. Dalam arti lain semiotika itu mempelajari sistem-sistem, aturanaturan , dan konveksi-konveksi yang memungkinkan tanda-tanda tersebut mempunyai arti. Ratna (2013: 97) mengungkapkan bahwa semiotika berarti studi sistematis mengenai produksi dan interprestasi tanda, bagaimana cara kerjanya, apa manfaatnya terhadap kehidupan manusia. Barthes (dalam Ratna, 2013: 97) menambahkan bahwa ide sentral dalam semiotika adalah konsepsi tertentu atau particular dari sebuah tanda (sign) yang seringkali didefinisikan sebagai ikatan antara penanda (signifier) dan petanda (Signified).

Jaranan adalah kesenian rakyat atau tarian penunggang kuda (jaran). Pada mulanya Jaranan bukanlah sebuah seni pertunjukan, bukan pula dinamakan kesenian karena memang zaman dulu belum dikenal istilah kesenian. Jaranan bagian dari ritual menolak bala, mengatasi berbagai musibah, meminta kesuburan pada lahan pertanian, mengharap keberhasilan panen, dan juga supaya masyarakat aman dan tenteram. Pada zaman primitif terdapat kepercayaan bahwa kerusakan lingkungan, wabah penyakit, bencana alam dan sebagainya terjadi karena kekuatan roh nenek moyang. Seiring dengan perjalanan waktu, setiap musibah, bencana atau berbagai masalah dalam kehidupan dihubungkan dengan roh nenek moyang itu disusun menjadi serangkaian cerita yang berkembang menjadi mitos yang diyakini oleh masyarakat. Kemudian dilakukan upacara dengan tujuan agar musibah tidak datang lagi. Kejadian yang berlangsung berulangkali kemudian berkembang menjadi berbagai simbol yang digunakan untuk kegiatan ritual. Maka dari itu dilakukan pengkajian tuturan Mantra Jaranan pada masyarakat suku Jawa di Desa Perangat Baru Kecamatan Marangkayu menggunakan analisis semiotika, yang memang dimana adat dan istiadat atau kebudayaannya masih sangat kental dan masih sering dilaksanakan pertunjukan jaranan.

Penelitian ini dilakukan dengan rumusan masalah dan tujuan untuk mengetahui ikon, indeks dan simbol dalam Tuturan Mantra Pada Tradisi Pertunjukan Jaranan di Desa Perangat Baru Kecamatan Marangkayu Kabupaten Kutai Kartanegara Provinsi Kalimantan Timur

\section{PENYAJIAN DATA}

\section{Mantra}

Sun Puji Maring Pangeran Mugi Kadang Mitro Sami

Suro Diro Joyo Diningrat Lebur Dening Pangastuti Kula puniki kajeng nedha NYUWUN ijin supados karo Gusti Allah

Dipunsukani kelancaran lan kawilujengan lebeting pementasan jaranan wanci[wekdal] puniki [MENIKA]

Wes wancine poro bopo toto sesaji, sesaji ingkang dipun nyuwun pamit

Wilujeng dugi salam rahajeng kangge para simbah sesepuh, danyang, nyai danyang

Kita badhe nedha ijin lan nyukani hidangan sesaji supados dipunsukakaken kelancaran lan perlindungan saking bab ingkang mboten kita kajengi.

Mugi-mugi lebeting pementasan puniki mboten wonten pambengan setunggal napa mawon saking awal dumugi bibaripun pementasan

lan tetep lebet lindungan gusti allah

Dugia para sesepuh, danyang, nyai danyang.

Kalih [kaliyan] mambet asap dupa lan sela ikutilah irama gending

Lan kula sukani ijin kangge ngrasuki para ringgit wayangipun kula

Lan bilih kula ngengken sampeyan medal saking badan wayangipun kula

Keluarlah wangsul dhateng asalipun sampeyan inggil ijin lan kuasanipun kula.

Bissmillahirrohmanirrohiim.

Assalamualaikum Wr.Wb.

Sugeng rawuh Poro simbah sesepuh, Danyang, Nyai Danyang teng seputaran desa Perangat Baru Niat ingsun manjing ingkang kulo si jabang bayine 
Badhe ngundang sang hyang moyo kakang kawah adi ari ari papat jejer kalimo pancer

Ingsun Ingkang kulo aturi rawuh simbah sesepuh leboni ing jero badan si Jabang bayi ne bocah wayang iki (kabeh) (nama pemain / dalam keseluruhan) krono Allah

Bilih asalipun sampeyan saking latu kembalilah dados latu

Bilih asalipun sampeyan saking toya kembalilah dados toya

Bilih asalipun sampeyan saking siti kembalilah dados siti

yBilih asalipun sampeyan saking angin kembalilah dados angin

Dugi sae sae wangsul kalih[kaliyan] sae sae

Bilih sampeyan badhe ndamel resah sampeyan badhe hancur lebur inggil ijin Allah

Lailalahaillah Muhammadar Rasulullah Allahu Akbar

Sugeng rawuh simbah sesepuh

Kula arep nyingkirke udan

Ojo sampek Nibo setetes, bun Bismillah hirohman nirohim

Aku pasang Janur kuning supoyo semeblak koyo Geni

Adoh koyo lintang padange koyo rembulan

Aku arep pasang Lombok abang iki

Kanggo gawe nunggoni Simbah Sesepuh

\section{ANALISIS DATA}

Ikon

\section{Pangeran}

Terjemahan: Sang Pencipta

Pada tuturan "Pangeran", merupakan sebuah ikon yang menggambarkan hubungan antara pawang dengan Sang Pencipta, dimana pawang memuja kepada Sang Pencipta (penanda) yang merupakan gambaran langsung dari petanda yang berkuasa memberikan kelancaran dalam pertunjukan Jaranan.

\section{Sesaji}

Terjemahan: Sesaji

Pada tuturan "Sesaji" sebuah ikon karena merupakan tanda atau alat perlengkapan dalam sebuah pertunjukan Jaranan, dimana pawang mulai menunjukan tanda yang mereka siapkan yaitu sesaji sebagai penanda dari petanda yaitu alat untuk memanggil para leluhur untuk meminta izin.
Terjemahan: dupa dan kemenyan

Pada tuturan "dupa lan sela" merupakan sebuah ikon karena berisi tuturan yang menunjukan sebuah dupa dan kemenyan yang merupakan tanda atau alat perlengkapan dalam pertunjukan Jaranan, dimana pawang menyiapkan dupa dan kemenyan sebagai penanda untuk memanggil roh-roh para leluhur masuk kedalam para pemain sebagai petandanya.

\section{Indeks}

Sun Puji Maring Pangeran Mugi Kadang Mitro Sami

Terjemahan: Saya memuja kepada Sang Pencipta atau Tuhan Semoga diberikan berkah atau kelancaran kepada saudara semua

Pada tuturan ini merupakan sebuah indeks karena memiliki hubungan sebab-akibat antara pawang dengan Sang Pencipta pawang memohon kepada sang pencipta dengan tujuan agar diberikan kelancaran dalam pertunjukan Jaranan.

\section{Suro Diro Joyo Diningrat Lebur Dening} Pangastuti

Terjemahan: Segala kesempurnaan hidup dapat diluluhkan dengan budi pekerti luhur

Pada tuturan ini merupakan sebuah indeks karena memiliki hubungan sebab-akibat antara penanda dan petandanya. Dimana kesempurnaan hidup sebagai petanda dan budi pekerti luhur sebagai penandanya yang artinya kesempurnaan hidup seseorang harus didasari dengan sebuah pijakan sifat budi pekerti luhur agar hidupnya selalu lancar.

nyukani hidangan sesaji supados dipunsukakaken kelancaran lan perlindungan

Terjemahan: memberikan suguhan sesaji agar diberikan kelancaran dan perlindungan

Pada tuturan ini merupakan sebuah indeks karena memiliki hubungan sebab-akibat antara penanda dan petandanya. Dimana pawang memberikan suguhan sesaji sebagai penanda kepada leluhur, dan sebagai petandanya agar diberikan perlindungan dalam pertunjukan.

ikutilah irama gending lan kula sukani ijin kangge ngrasuki para ringgit wayangipun kula

Terjemahan: ikutilah irama gending Saya izinkan untuk merasuki para wayang wayangku

Pada tuturan ini merupakan sebuah indeks karena memiliki hubungan sebab-akibat antara penanda 
dan petandanya. Dimana pawang meminta agar para sesepuh mengikuti irama gending sebagai penandanya, yang artinya sebagai petandanya adalah pawang meminta agar roh leluhur masuk ke dalam tubuh pemain jaranan.

\section{Simbol}

\section{Janur Kuning}

Terjemahan: Janur Kuning

Merupakan sebuah simbol penanda dari petanda yang tidak memiliki hubungan alamiah, namun memiliki hubungan secara konvensional yaitu melambangkan sebuah kekuatan dari kelompok tradisi Jaranan itu sendiri. Kelompok kesenian Jaranan ini dilambangkan dengan tegaknya janur kuning yang kokoh dan memiliki kekuatan mental dan kekuatan fisik yang tidak bisa digoyahkan oleh siapapun.

\section{Semeblak koyo Geni}

Terjemahan: Dipukul kayak api

Simbol tersebut dituturkan oleh pawang sebagai tingkah laku pawang hasil dari memukulkan janur kuning ke tanah kayak api, yang diartikan sebagai pemisah atau penghalang agar tidak terjadi turun hujan

\section{Jabang bayine}

Terjemahan: Pemain Jaranan

Merupakan sebuah simbol penanda dari petanda yang tidak memiliki hubungan alamiah, namun memiliki hubungan secara konvensional yaitu sebuah simbol dari kesepakatan masyarakat, bahwa makna dari jabang bayine adalah para pemain jaranan yang melakukan pertunjukan jaranan.

\section{Sesaji}

Terjemahan: Sesaji

Pada tuturan "Sesaji” tidak hanya menjadi sebuah ikon tetapi bisa juga menjadi sebuah simbol karena merupakan tanda atau alat perlengkapan dalam sebuah pertunjukan Jaranan, dimana sesaji sebagai simbol berupa penghargaan terhadap para danyang atau leluhur yang ada di daerah tersebut.

\section{HASIL PENELITIAN}

Berdasarkan analisis data mantra Jaranan, dapat diketahui hasil penelitian dalam menganalisis semiotika dalam tuturan mantra pertunjukan Jaranan di desa Perangat Baru dengan menggunakan analisis semiotika yang berdasarkan penanda dan petandanya dibagi menjadi tiga tanda yaitu, ikon, indeks, simbol. Berikut hasil penelitian analisis semiotika berupa ikon, indeks, simbol:

\section{Ikon}

Terdapat 3 tuturan ikon yaitu, berupa tuturan mantra Pangeran, Sesaji, Dupa lan sela

\section{Indeks}

Terdapat indeks yang membuktikan atau menggambarkan adanya hubungan kasual (sebab-akibat) dalam pertunjukan Jaranan, Terdapat 4 indeks yaitu Sun puji maring pangeran Mugi Kadang Mitro Sami, Suro Diro Joyo Diningrat Lebur Dening Pangastuti, nyukani hidangan sesaji supados dipunsukakaken kelancaran lan perlindungan, kula sukani ijin kangge ngrasuki para ringgit wayangipun kula

\section{Simbol}

Terdapat 3 simbol yaitu simbol berupa tuturan mantra Jaranan Janur kuning, Irama gending, si jabang bayine

\section{PEMBAHASAN}

Semiotika dalam Tuturan Mantra Tradisi Pertunjukan Jaranan

Hasil penelitian ini penulis mendapatkan informasi tentang pertunjukan Jaranan serta tuturan mantra. Data tuturan mantra ini berjumlah 3 data. Data penelitian ini didapat langsung dari hasil rekaman wawancara penulis dengan seorang pawang dan juga ketua organisasi. Penulis menganalisis data mantra untuk mendapatkan kajian semiotika yang berupa ikon, indeks, dan simbol. Dari hasil analisis penulis mendapatkan 15 Ikon, 14 Indeks, dan 17 Simbol.

\section{Ikon}

Pangeran, sebagai tanda ikonis yang berarti Sang Pencipta, merupakan ungkapan sesuatu yang diyakini, dipuja, dan disembah oleh manusia sebagai yang Maha Kuasa atau Maha Perkasa. Hal tersebut bertujuan untuk memohon atau memuja kepada Tuhan untuk membantu kelancaran dalam pertunjukan Jaranan dan untuk meminta keberkahan untuk seluruh masyarakat agar terhindar dari bala atau musibah.

Sesaji (Sesajen), mengandung ikon yaitu sebagai jembatan penghubung antara dunia manusia (Pawang) dengan Tuhan. Hal tersebut bertujuan sebagai persembahan kepada para danyang atau roh-roh halus. Dalam peristiwa pementasan memiliki fungsi 
fungsi khusus. Pertama, sebagai salah satu elemen pemanggil arwah yang akan bersemayam atau manjing kepada pemain sehingga menimbulkan kesurupan. Kedua, sajen juga berfungsi terkait sebagai persembahan kepada para danyang yang berkait dengan hajat pementasan.

Dupa lan sela. Mengandung ikon yaitu proses awal yang dilakukan pawang dalam melaksanakan Pertunjukan Jaranan yaitu dengan membakar Dupa. Hal ini bertujuan untuk pesuruh agar memanggil para leluhur untuk membantu dan turut campur tangan dalam pertunjukan Jaranan.

\section{Indeks}

Mugi Kadang Mitro Sami pada mantra Jaranan indeks dalam mantra ini digambarkan oleh seorang pawang yang meminta permohonan kepada Tuhan Yang Maha Esa semoga diberikan berkah untuk seluruh masyarakat didesa Perangat Baru agar terhindar dari bala atau menolak bala.

Suro Diro Joyo Diningrat Lebur Dening Pangastuti mengandung indeks yaitu memiliki hubungan sebab-akibat antara penanda dan petandanya. Dimana kesempurnaan hidup sebagai petanda dan budi pekerti luhur sebagai penandanya yang artinya kesempurnaan hidup seseorang harus didasari dengan sebuah pijakan sifat budi pekerti luhur agar hidupnya selalu lancar.

Nyukani hidangan sesaji supados dipunsukakaken kelancaran lan perlindungan, mengandung indeks yaitu tingkah laku pawang memberikan suguhan sesaji kepada Leluhur, hal ini bertujuan untuk memanjatkan doa yang ditujukan kepada Tuhan agar dilancarkan dalam pementasan sehingga tidak terjadi hal-hal yang tidak diinginkan. Doa untuk para leluhur juga dipanjatkan oleh pawang untuk meminta restu agar diberi perlindungan serta kemudahan dalam mendatangkan dan mengembalikan roh-roh yang akan merasuki para penari kuda lumping. Ritual kepada leluhur intinya memohon ijin pada yang menguasai tempat tersebut yang biasanya ditempat terbuka supaya tidak menggangu jalannya pertunjukan dan demi keselamatan para penarinya.

Kula sukani ijin kangge ngrasuki para ringgit wayangipun kula merupakan indeks yaitu tingkah laku pawang yang meminta Leluhur atau roh-roh leluhur agar masuk ke raga atau tubuh para pemain Jaranan. Hal ini bertujuan agar raga si pemain Jaranan ini mengalami kesurupan.

\section{Simbol}

Janur Kuning (Janur Kuning), melambangkan sebuah kekuatan dari kelompok tradisi Jaranan itu sendiri. Kelompok kesenian kuda lumping ini dilambangkan dengan tegaknya janur kuning yang kokoh dan memiliki kekuatan mental dan kekuatan fisik yang tidak bisa digoyahkan oleh siapapun.

Geni (Api), simbol tersebut dituturkan oleh pawang sebagai tingkah laku pawang hasil dari memukulkan janur kuning ke tanah, yang diartikan sebagai pemisah atau penghalang agar tidak terjadi turun hujan. Hal ini secara jelas menunjukan bahwa simbol bahasa yang digunakan merupakan hasil kesepakatan masyarakat sekitar.

Jabang bayine (Pemain Jaranan), merupakan sebuah simbol dari kesepakatan masyarakat, bahwa makna dari jabang bayine adalah para pemain jaranan yang melakukan

\section{Hubungan Pertunjukan Jaranan dengan masyarakat}

Masyarakat desa Perangat Baru memiliki aturan-aturan dalam kehidupan yang merupakan tradisi turun-temurun yang sudah disepakati dalam kehidupan bermasyarakat di desa Perangat Baru, selain itu untuk menghormati dan menghargai segala tradisi warisan nenek moyang atau leluhur jaman dulu. Salah satunya dengan pertunjukan Jaranan.

Banyak masyarakat yang sangat antusias menyaksikan kesenian Jaranan, mulai dari orang tua hingga anak-anak yang datang ke lokasi pertunjukan. Karena kesenian yang satu ini juga tidak membosankan untuk menonton pertunjukan Jaranan. Banyak penonton yang terhibur dengan atraksi-atraksi para pemain, misalnya pemain salto berulangulang kali, makan beling, mengupas kulit kelapa dengan gigi, dan banyak atraksi ekstrem lainnya.

Setiap tradisi yang dilaksanakan di dalamnya selalu melibatkan masyarakat. Dalam melaksanakan tradisi pertunjukan Jaranan juga memerlukan perlengkapan, pemimpin pertunjukan, pawang, dan penanggung acara pertunjukan. Pertunjukan Jaranan wajib dilaksanakan masyarakat di Desa Perangat baru, biasanya dilaksanakan setiap bersih-bersih desa atau 17 agustusan, dikarenakan dalam pertunjukan Jaranan ini masyarakat Perangat Baru memohon agar terhindar dari bala atau musibah selama hidup.

Hal ini muncul sebuah hubungan antara penutur atau pawang dan pemain atau antara 
pawang dan orang yang mempunyai acara atau hajat dan masyarakat. Sehingga sikap saling tolang menolong hadir dan memperkuat hubungan yang tadinya biasa saja menjadi hubungan yang lebih dekat. Hubungan sosial juga terjadi karena kesenian Jaranan merupakan kesenian yang menghibur. Antara pemain dan penonton terjadi interaksi yaitu pemin sebagai orang yang menghibur dan penonton orang yang dihibur. Dan dapat melestarikan budaya adat dan istiadat. Jaranan bagian dari ritual menolak bala, mengatasi berbagai musibah, meminta kesuburan pada lahan pertanian, mengharap keberhasilan panen, dan juga supaya masyarakat aman dan tenteram.

\section{Perbedaan Antara Jaranan Yang Dianalisis Dengan Jaranan Yang Ada di Jawa}

Perbedaan Jaranan yang ada di Prangat Baru dengan jaranan di jawa. Jaranan adalah salah satu kesenian yang cukup tersebar di beberapa daerah di Indonesia. Jaranan pada dasarnya adalah sebuah kesenian rakyat yang digemari oleh masyarakat, khususnya di desa Perangat Baru dan sekitarnya, menggunakan seni Jaranan Senterewe. Adapun persamaan dan perbedaan antara Jaranan asli jawa dengan jaranan senterewe yang ada di Prangat Baru. Masing-masing akan selalu selaras dengan karakteristik budaya masyarakat dimana kesenian itu hidup dan berkembang.

Seperti halnya dengan kesenian jaranan yang lain, Jaranan Senterewe yang ada di Prangat Baru juga merupakan seni tari yang dalam prakteknya menggunakan properti berupa kuda-kudaan yang terbuat dari bambu (jaran atau kuda kepang). Tarian ini menggambarkan prajurit berkuda yang sedang berlatih perang menguji ketangkasan, mahir dan kemudian diuji kembali untuk berburu binatang. Beberapa wujud binatang dalam Jaranan Sentherewe meliputi Celengan (Babi Hutan) dan Barongan sebagai penggambaran ular naga. Selain itu, Jaranan Sentherewe juga tidak terlepas dari kuatnya aroma mistis. Pertunjukan biasanya selalu diawali dengan mantra-mantra, memakai sarana sesaji (sajen), hingga pada puncaknya sering terjadi adegan kerasukan (ndadi). Seni tarian senterewe yang dikreasikan menjadi jaranan campursari. Yang dimana didalamnya ada beberapa modernisasi dalam bentuk solah (gerakan pemain) yang mengikuti irama tabuhan gamelan sehingga tercipta seni indah yang selaras. Terkadang juga menggunakan properti kendang jaipong untuk menambahkan irama atau lantunan yang baru sehingga bisa menghipnotis para pemain dan penonton untuk menikmati kesenian tersebut. Sedangkan Jaranan campursari adalah Untuk mengiringi seni tari ini, digunakan alat musik pokok yakni kendang (gendang), bonang (gamelan kempul), serompet (terompet) dan saat ini telah mengalami perkembangan dengan ditambahkan jidor (bedug yang terbuat dari bahan logam - bukan kayu), simbal, gamelan dan lain-lain.

Jaranan Campursari Turonggo Purwo Budoyo menggunakan seni jaranan senterewe yang telah dikreasikan dalam bentuk jaranan campursari didalam jaranan tersebut tidak terlalu banyak mengubah dari jaranan versi aslinya. Beberapa hal yang dikreasikan dari versi aslinya antara lain, yaitu solah, pakaian yang digunakan penari, penambahan instrumen kendang jaipong, penyebutan mantra yang berbeda dalam segi bahasa jawa halus atau kromo inggil, perbedaan para sesepuh atau danyang yang berbeda disetiap daerah.

\section{KESIMPULAN}

Berdasarkan permasalahan dan tujuan yang telah dirumuskan pada bab-bab sebelumnya dalam penelitian ini dengan penyajian data, analisis data dan pembahasan, maka dapat disimpulkan bahwa terdapat 3 bentuk ikon, 4 bentuk indeks, dan 3 bentuk simbol pada tuturan mantra Pertunjukan Jaranan di desa Prangat Baru

\section{REFERENSI}

Amir, Adriyetti. 2013. Sastra Lisan Indonesia. Yogyakarta

Aminudin. 2020. Pengantar Apresiasi Karya Sastra. Bandung: Sinar Baru Algensindo

Anugrah, Diana. 2016. Analisis Semiotika Terhadap Prosesi Pernikahan Adat Jawa "Temu Manten" di Samarinda. EJurnal Ilmu Komunikasi.4. (1), 319330.

Barthes, Roland. 1994. Elements Of Semiology. Terjemahan: Khafie Nazaruddin. Yogyakarta. Perpustakaan Nasional

Dilistone, F.W. 1986. The Power Of Symbols. SCM Press Ltd., London.

Endraswara, Suwardi. 2006. Metodologi Penelitian Kebudayaan. Yogyakarta Endraswara, Suwandi.2013. Teori Kritik Sastra. Yogyakarta: Caps

Ezmir dan saifur Rohman. 2016. Teori dan Pengajaran Sastra. Jakarta: Rajawali Press.

Nurgiyantoro, Burhan. 2010. Teori 
Pengkajian Fiksi. Yogyakarta

Ratih, Rina. 2017. Teori dan Aplikasi Semiotika.

Yogyakarta: Pustaka Belajar

Ricoeur, Paul. 2012. Teori Interpretasi. Texas: Yogyakarta, Ircisod

Riduwan. 2014. Metode dan Teknik Menyusun Proposal Penelitian. Bandung: Alfabeta CV.

Sugiyono. 2014. Memahami Penelitian Kualitatif. Bandung: Alfabeta CV.

Sugiyono. 2020. Motode Penelitian Kualitatif. Bandung: Alfabeta CV

Sulistiyorini, Dwi dan Eggy Fajar Andalas. 2017. Sastra Lisan. Malanng: Madani.

Sumandiyo, H. (2012). Seni Pertunjukan Dan Masyarakat Penonton. Yogyakarta: BP ISI Yogyakarta. Terjemahan Oleh A. Widyamartaya. 2006. Yogyakarta. 